\title{
SEISMIC DAMAGE MECHANISMS FOR CHURCHES AND DAMAGE SEQUENCE: CONSIDERATIONS FROM A CASE STUDY
}

\author{
MARIA A. PARISI ${ }^{1 *}$, YLENIA ANZILOTTI ${ }^{1}$, GRACE I. FUENTES RIVERA ${ }^{1}$, \\ GESSICA SFERRAZZA PAPA ${ }^{1}$, STEFANO BARBÒ ${ }^{1}$ \\ ${ }^{1}$ Department of Architecture, Built Environment and Construction Engineering (ABC) \\ Politecnico di Milano \\ Piazza Leonardo da Vinci, 32, 20133 Milano, Italy \\ *e-mail: maria.parisi@polimi.it
}

Keywords: Churches, Masonry, Seismic damage, Damage mechanism, Progressive failure

\begin{abstract}
Several high-intensity earthquakes have occurred in Italy in the last decades, causing considerable damage to architectural heritage and pointing out the particularly high seismic vulnerability of masonry churches. A significant research effort has been devoted to develop specific methods for the damage analysis and the seismic vulnerability assessment of these assets. An abacus of damage mechanisms recurring in the church structural components has been developed and has become an important reference in rapid assessment procedures as well as in more detailed analyses. In this perspective, the damage occurred to a church during the Pianura Padana Emiliana (Emilia) Earthquake of 2012 is analyzed here. The damage pattern reproduced, indeed, situations listed in the abacus of mechanisms. The seismic response of the church has been analyzed with different numerical approaches, with complete and with partial models that have allowed an appreciable understanding of the global behavior and of the modality of damage progressing into the mechanisms. The use of vector graphics software tools for $3 D$ modelling that have become available in recent times has allowed to thoroughly understand the constructional complexity of the asset and, consequently, to develop simpler but structurally significant models for numerical analysis.
\end{abstract}

\section{INTRODUCTION}

TThe numerous high-intensity earthquakes that have occurred in Italy in the last decades have caused considerable damage and losses to the architectural heritage. The damage toll taken by earthquakes has been particularly heavy on historic masonry churches, which are especially vulnerable to seismic action due to their structural characteristics. These circumstances have conveyed a significant research effort into studying specific methods for

-analysing the damage to churches,

-in a prevention phase, assessing their seismic vulnerability [e.g. 1],

-assessing the validity of interventions for damage repair and for structural improvement.

The method of limit equilibrium has proven to be a powerful tool for both damage and vulnerability analyses. An abacus of possible limit mechanisms that recur in the church structural components, or macro-elements, has been developed. It is founded on a very ample 
base of observational data derived from different earthquakes and in different regions, thus covering differences in constructional traditions and typologies, and it has become a widely used reference in rapid assessment procedures as well as in more detailed analyses. Specifically, a survey form is used to collect information on what damage mechanisms have developed; for each mechanism, damage is graded referring to a scale from 1 to 5 , where 5 is the collapse state [2]. Extensive use of this reference in recent earthquakes has proven its general validity, but also indicated possible further developments. These may regard consideration of additional damage cases as well as a deeper understanding of the progression of mechanism development. To this purpose, the post-earthquake observation and analysis of damage cases remains a fundamental step for improving this additive knowledge.

Within this context, the damage occurred to a church during the Pianura Padana Emiliana Earthquake of 2012 that produced extended damage to these assets [3] is interpreted here. The church, built in the 18th century and located in a village in the province of Mantova, presented severe damage in different areas, especially in the vaults covering the three naves.

For these elements, the damage pattern reproduced situations listed in the abacus of mechanisms. The church façade, with an imposing tympanum according to the style of the time, instead, reported only initial damage from an out-of-plane rotation of the tympanum, and some more extended damage from a rotation of the entire façade, an unusual situation crossing two different mechanisms.

In order to investigate this case, a meaningful representation of the original ground motion is necessary. Earthquake recordings taken in the vicinity of the church for the two major shocks satisfied this 1
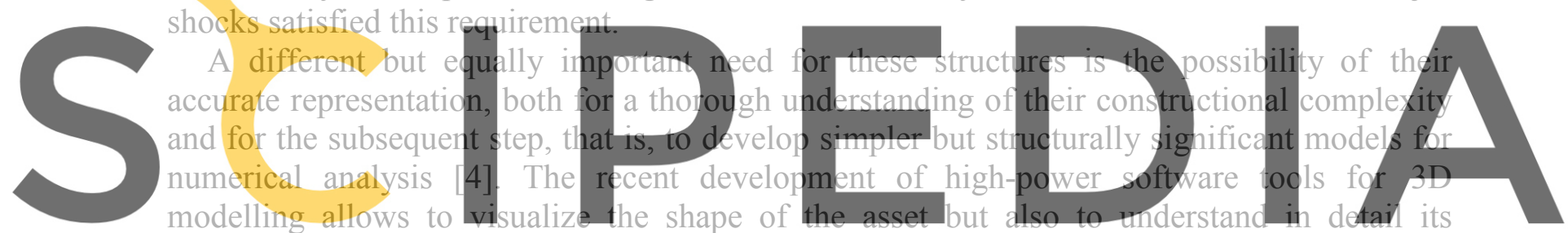

modelling allows to visualize the shape of the asset but also to understand in de
geometry and its

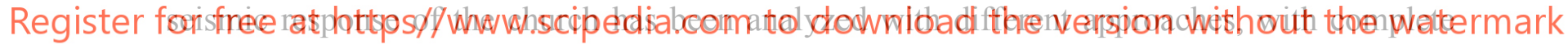
and with partial models that have allowed an appreciable understanding of the global behavior and of the modality of damage development, as described in the following sections.

\section{REFERENCE DAMAGE MECHANISMS FOR CHURCHES}

One of the most frequent damage modes in churches concerns the façade, which may fail in different and typical ways depending principally on its geometry, on the quality of its connection with side walls, on the presence of thrusts from the roof or other elements behind, and the main direction of motion. Figure 1 reports typical façade mechanisms, taken from the abacus mentioned above, with out-of-plane rotation of the entire façade wall or of the tympanum. These mechanisms will be found in the case study analyzed. In-plane shear modes may also occur in the façade element.

Another dominant failure mode associated to the transversal response of the building is the out-of-plane failure of the nave walls, summarized also in fig.1. This mode occurs particularly in those architectural styles where the walls of the central nave of three-nave churches are 
particularly slender, possibly with the presence of a clerestory. This failure mode may be the result of interaction with heavy roof trusses or be triggered by non-restrained thrusts from the arches and vault covering the central nave. It is particularly critical, as collapse of the top of the wall most often causes the collapse of the vault or deprives the roof trusses of support, resulting in their fall.

Vaults, which are structural elements particularly suitable to carry vertical loads, are particularly sensitive to lateral forces from seismic action: they develop crack patterns depending on the vault geometry.

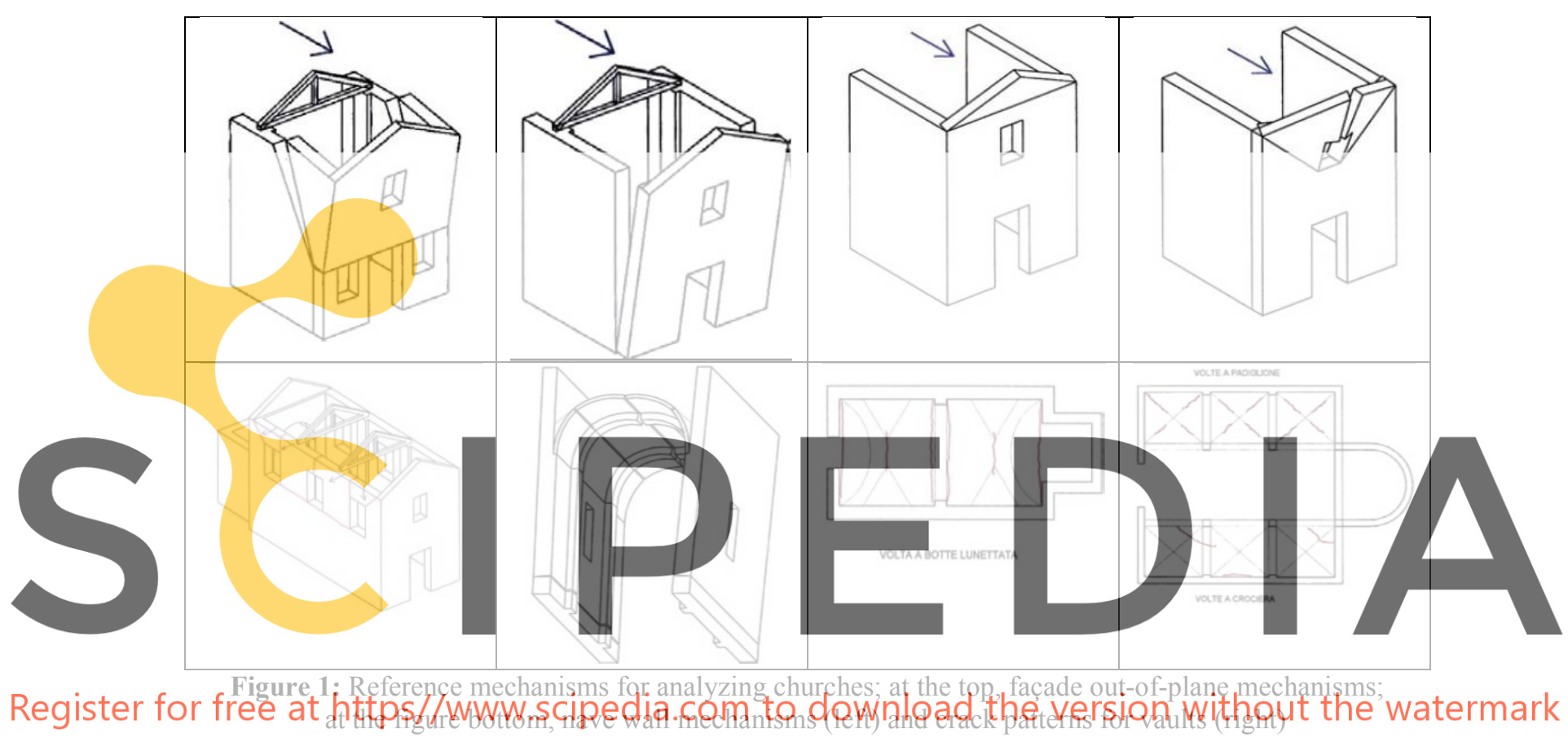

\section{THE EMILIA EARTHQUAKE OF 2012 IN THE PROVINCE OF MANTOVA}

In the month of May 2012, the territory of Emilia Romagna and nearby regions in northern Italy were hit by an earthquake sequence, with seven main shocks having a moment magnitude $M_{w}$ higher than 5. Five of them occurred between May 20 and May 29, 2012.

The region stricken by this earthquake had no history of frequent or strong earthquakes. The most significant one dated back to 1570 in Ferrara, in the eastern part of the area, and was estimated as of $\mathrm{M}_{\mathrm{w}}$ 5.46. The seismic hazard of the region had been classified at a low-tomoderate level only since 2003, when seismic design of buildings was enforced. Thus, until recently also the new buildings were not designed according to seismic requirements. Lack of awareness of seismic risk seems to have affected the traditional constructional practice that did not include provisions adopted in other parts of the country. This situation caused extended damage to new and old buildings in the Emilia region as well in the adjacent provinces of Mantova and Cremona, in Lombardy, where a signicant number of cultural heritage buildings and churches was damaged. 

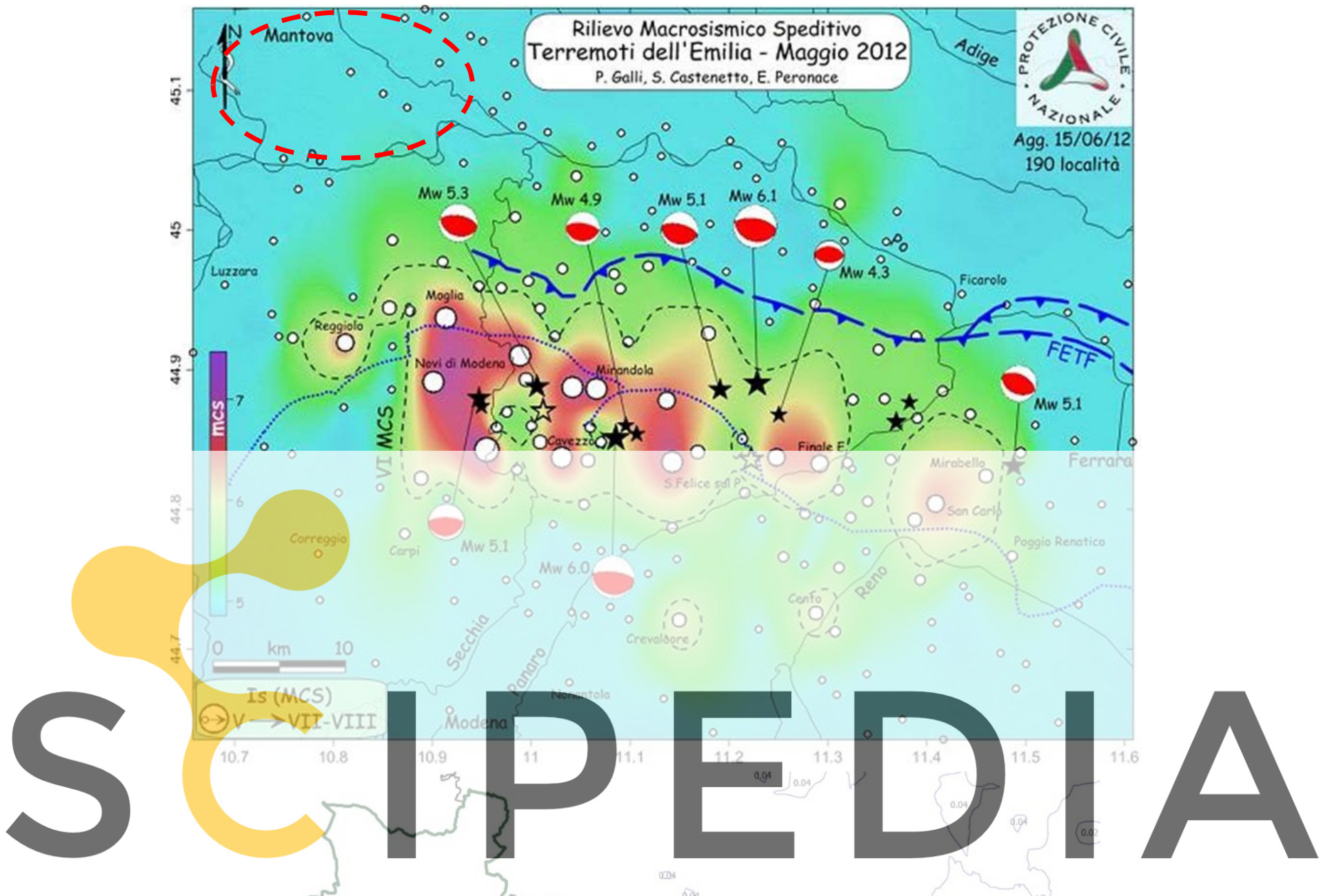

Register for free at https//www.scipedia.com to download the version without the watermark

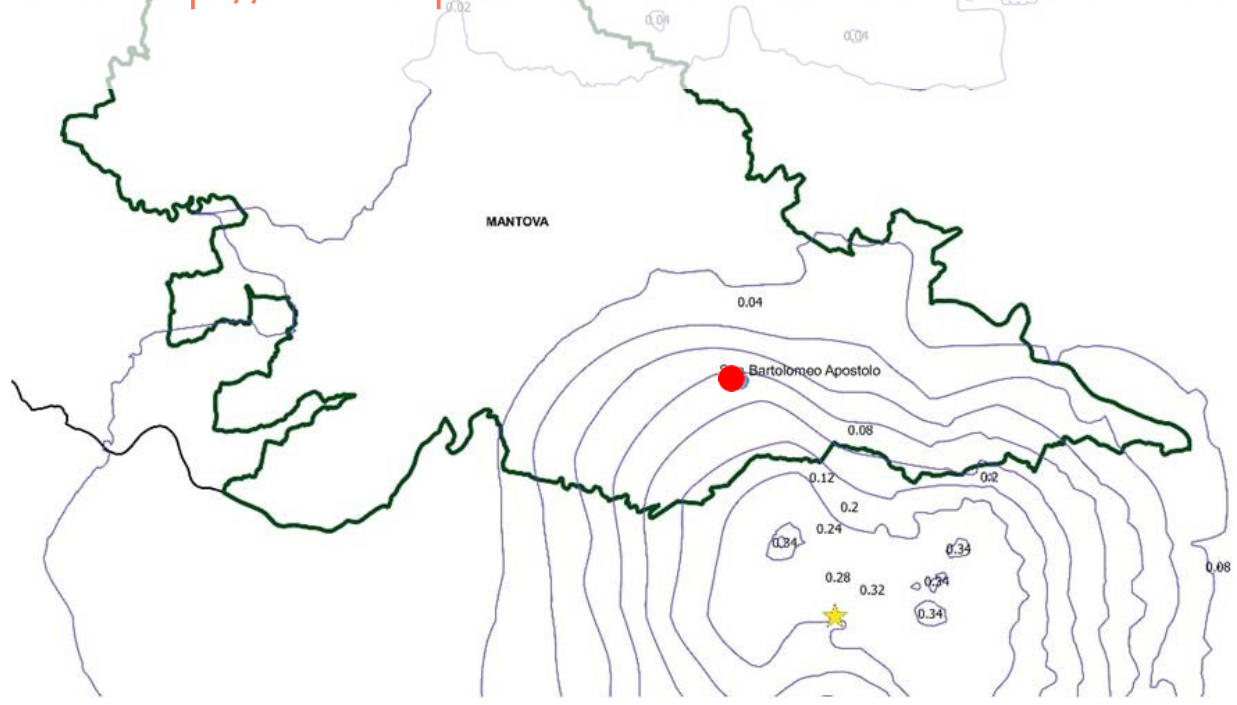

Figure 2: Map of the major events in the 2012 Emilia earthquake (top) and the isoseism map in the area of Mantova in the event of May 29 (bottom); the church of this case study is shown with a red dot 
With reference to fig. 2, top, showing the major events in the sequence, the province of Mantova is located NW. Here, the most damaging shocks have been those of May 29, which had a closer epicenter and which found a building stock already weakened by the previous events.

Several churches in the area were built in the local expression of the baroque style, having elements and proportions that made them particularly exposed to seismic damage. The church investigated here is representative of this typology. Its location is shown in fig.2, within the isoseism map of the May 29, 9:00 02 a.m. event.

\section{DAMAGE STUDY}

The earthquake series of 2012 severely damaged 129 churches of the diocese of Mantova, amounting to 42 percent of the total. Damage surveys that were carried out in the immediate post-earthquake period to assess the situation over the territory made reference to the abacus of possible mechanisms. While this reference has allowed homogeneity in treating and comparing the many cases examined, some situations that were difficult to interpret have suggested to investigate in more detail the damage occurred and the modality in which it developed.

\subsection{The church of San Bartolomeo at Quistello}

The church of San Bartolomeo at Quistello has been chosen for a study because it is

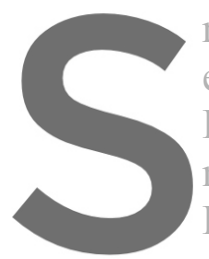
representative of many similar assets both in
extension and type of suffered damage. The f
Each space defined in the plan is covered by v
midplan, in a complex pattern shown in fig. 4 .
Reports on the historical documentation was a

which permitted to retrace interventions and modifications carried out at different times. A

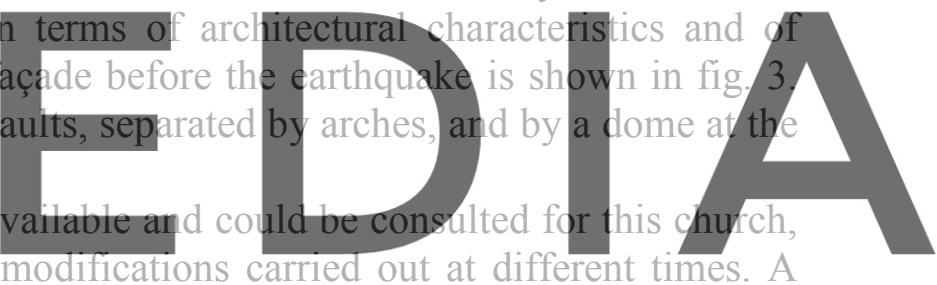
recent detailed study by diagnostic, testing evidenced a good quality of.brick masonry

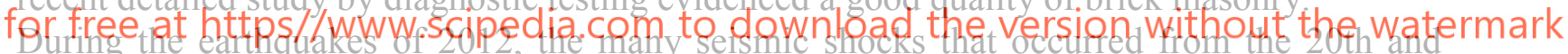

particularly on 29th of May heavily damaged the church that reported collapses of the vaults and wide cracks on many bearing walis of the central nave, as well as the collapse of the roof behind the façade. The event of the 20th of May caused out of plane, overturning cracks on the façade in the proximity of the gable and the overturning toward the interior of the marble element supporting the cross, at the top of the façade, that collapsed into the roof. The fall of such non-structural element caused damage to the roof behind the façade and to the counterfaçade vault underneath. This kind of damage was observed in other churches in the area.

The second important shock of the 29th of May, at 9:00 a.m., deteriorated further the situation. Many of the vaults collapsed, causing additional damage to decorations and other art elements below. The damaged vault behind the façade fell, entailing the collapse of the organ, see fig. 5.

Other elements and parts of the church were also severely damaged. Important cracks opened in the entablature above the arches along the central nave as well as in those between the chapels. In many cases they reached the vaults above, as in fig. 6. The apse developed numerous inclined cracks, which are frequently found in such element: a situation that has been listed in the abacus of typical mechanisms. 


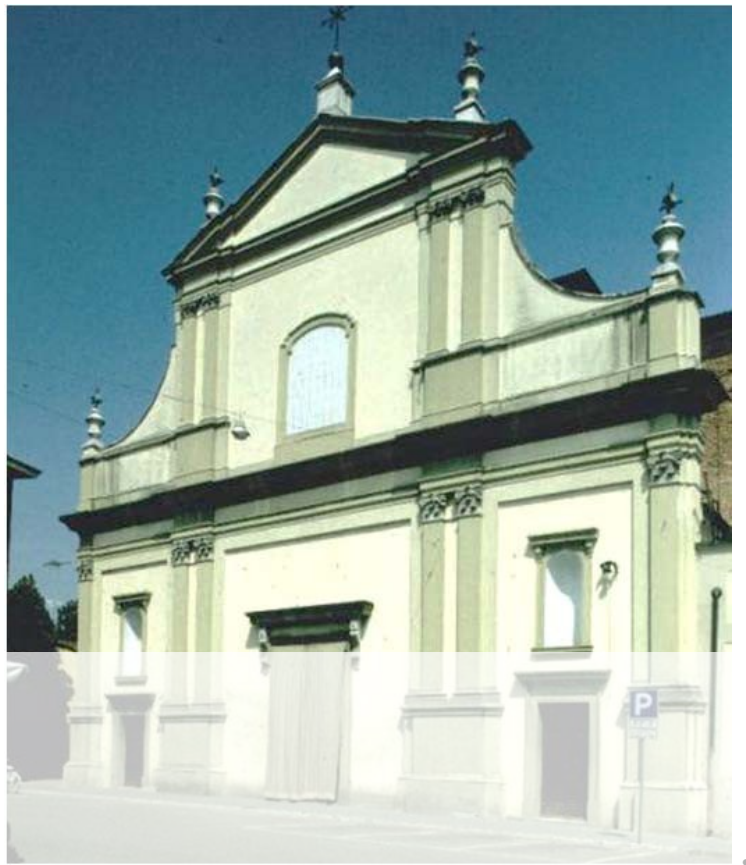

Figure 3: The church of San Bartolomeo Apostolo at Quistello
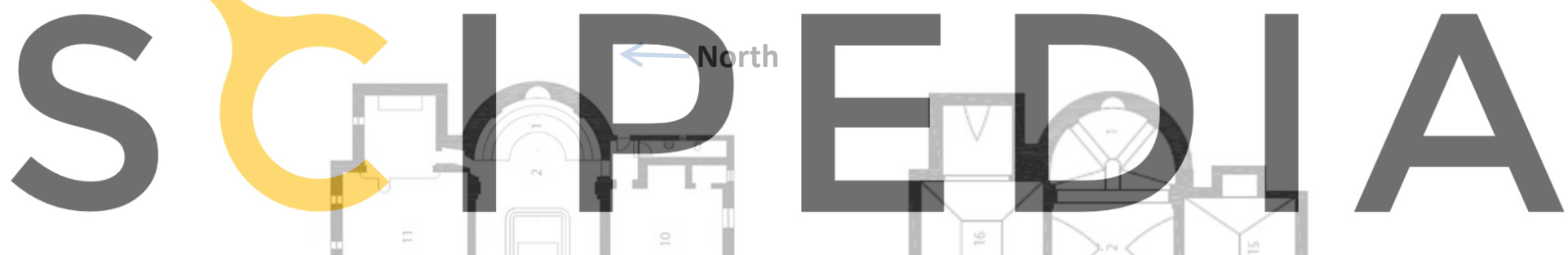

Register for free at https//www.scipedia.com to download the version without the watermark
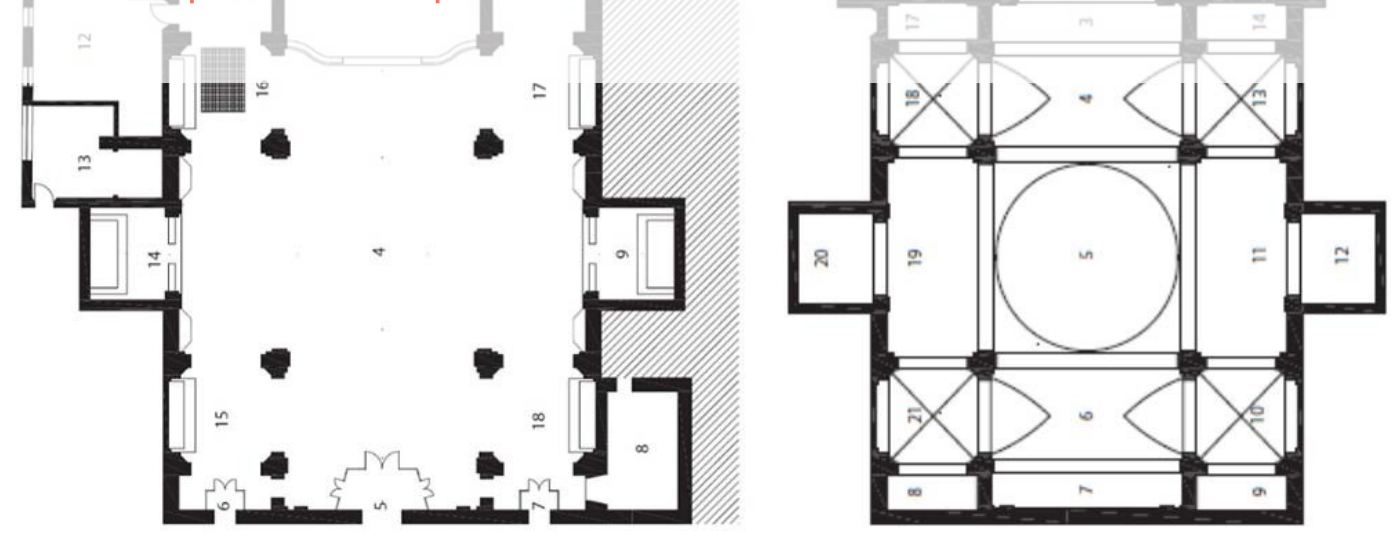

Figure 4: The plan and the vault system

The façade usually suffers severe damage, either locally due to overhanging parts and little restrained areas, or globally, when the façade is badly connected to the nave walls. This situation is frequent for architectural and construction reasons and usually evolves into the 
detachment and out-of-plane rotation of the entire façade wall [e.g. 5, 6]. Façade damage modes, for their importance, are the first indicated in the abacus of mechanisms. Here they are shown in fig. 1. Yet, in San Bartolomeo only some limited damage to the gable top was found, together with an initial global rotation of the façade, that is, two façade mechanisms seemed to have developed but the first only to a small extension. In order to investigate the structural behavior of the church and follow the development of its seismic response that brought to the observed damage, a series of numerical analyses were planned. A detailed geometric model and different numerical ones were developed to this purpose.

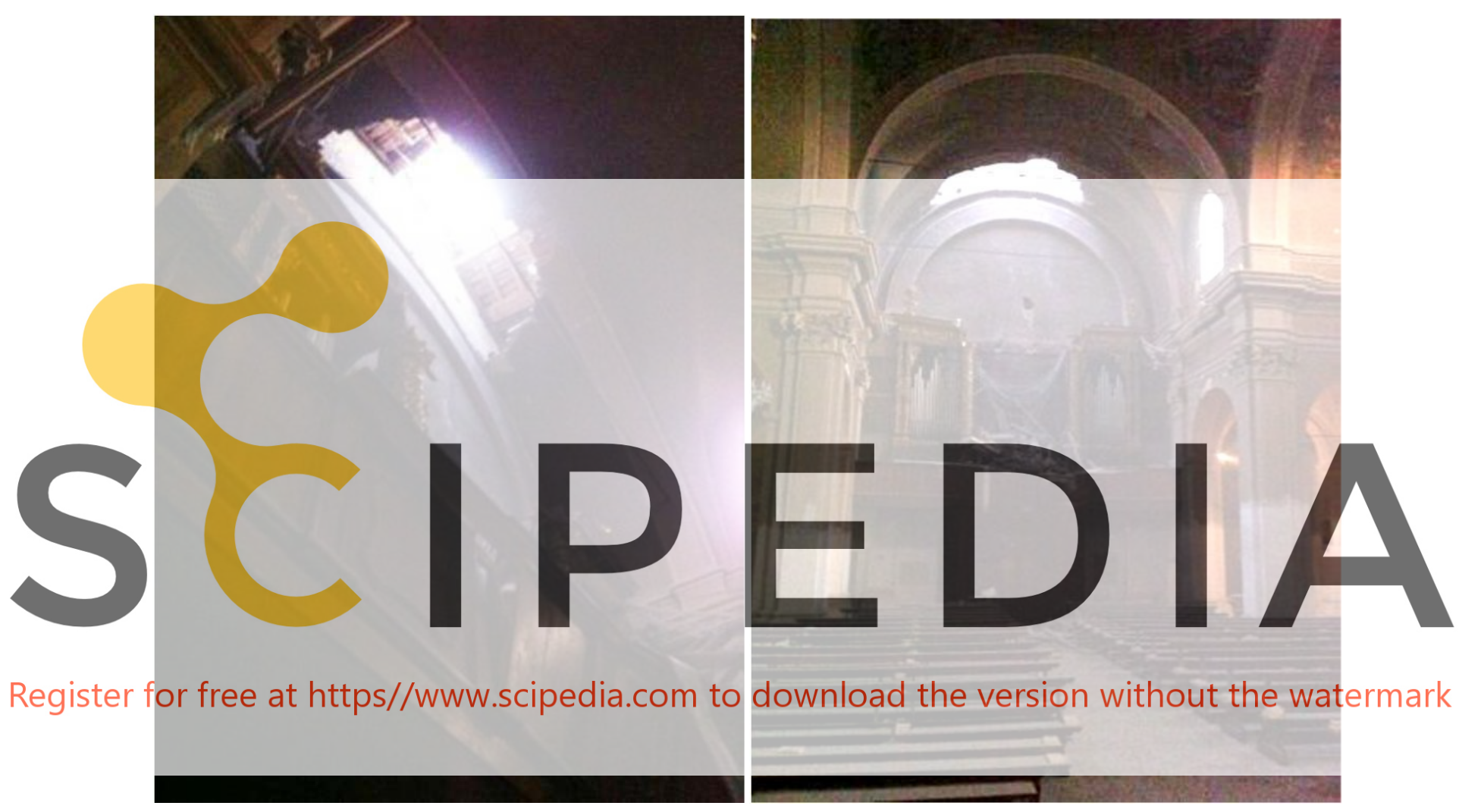

Figure 5: Collapse of the vault behind the façade
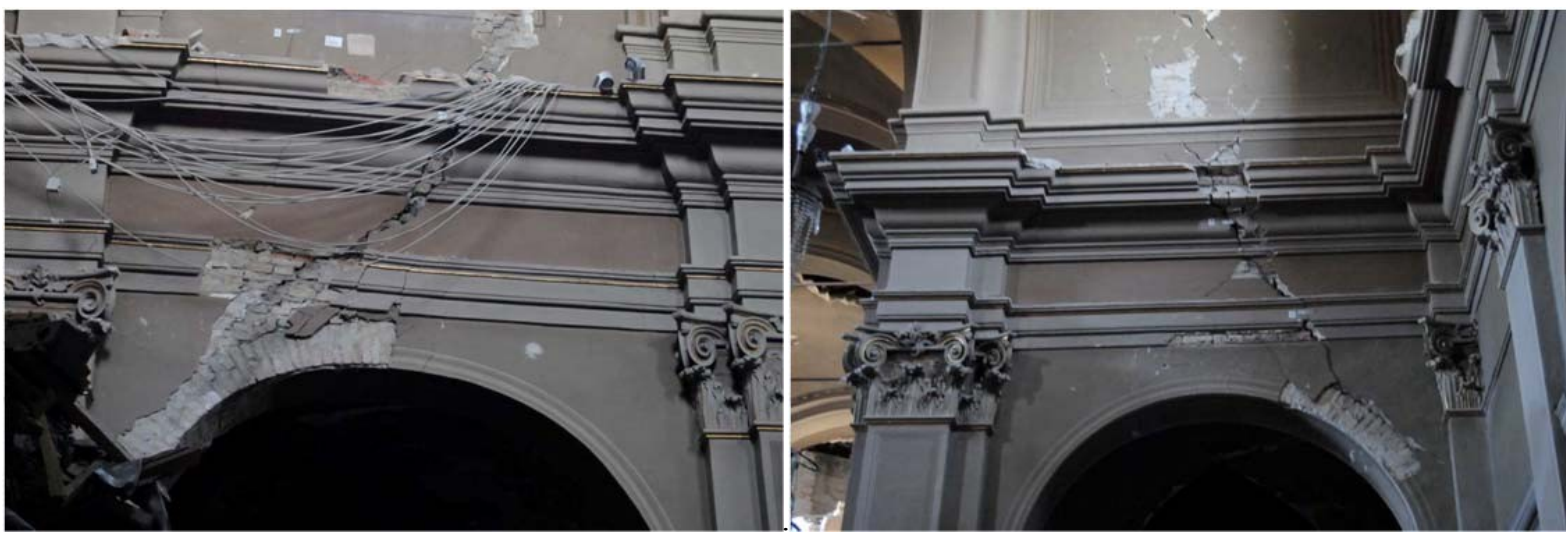

Figure 6: Cracks in the arches along the nave and transversal to it. 


\section{THE MODELS}

The information available on the building was basically in traditional two-dimensional formats. The creation of a three-dimesional (3D) model by vector graphics software [7] was a fundamental step toward a thorough understanding of the church in its construction process, its composition, as well as its present state. The correct representation of the vault system requires particular effort, yet this process brings to a deep understanding of the system in its complexity. In the development of the architectural model, attention was paid to select options that would facilitate the subsequent translation to a numerical model for finite element structural analysis. Figures 7 and 8 show global renderings of the architectural model and the finite element model, which was formed with over 103000 nodes and 57100 elements. Shell elements were used for vaults and solid elements for the other parts. The final model included the roof structure, following damage observations that indicated its positive interaction with walls in the response, [e.g. 81.

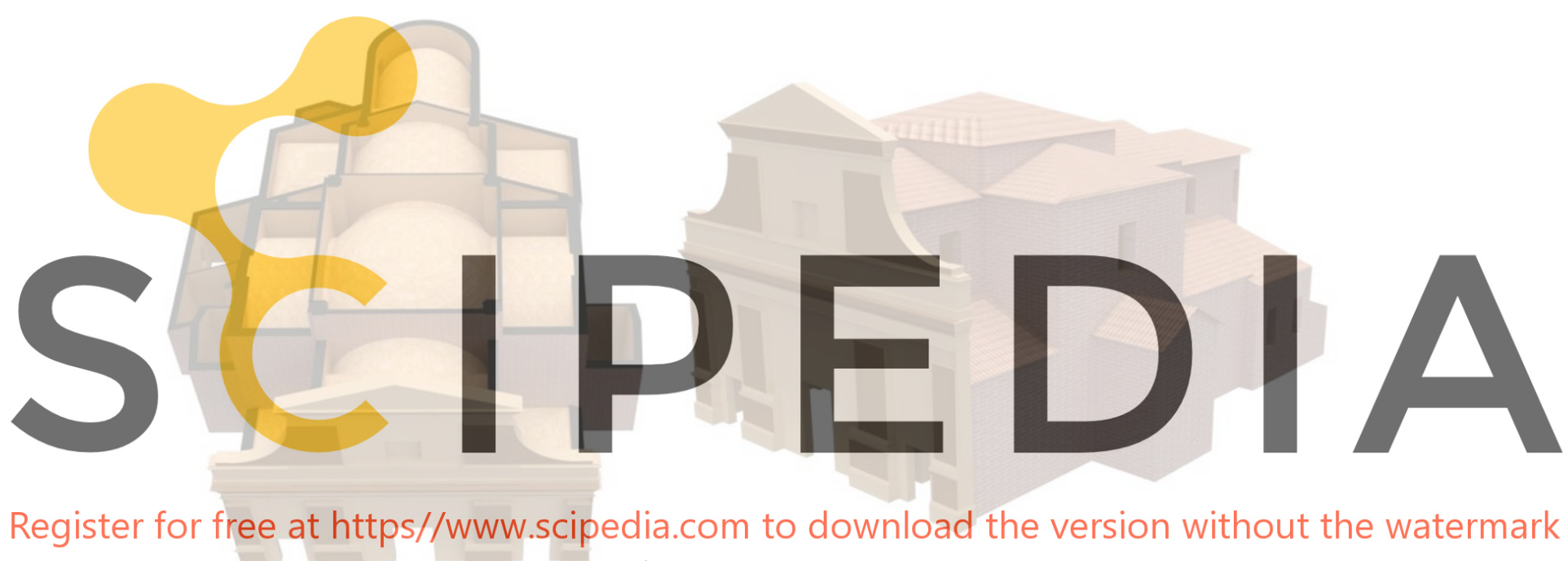

Figure 7: the vault system and a general view of the church model

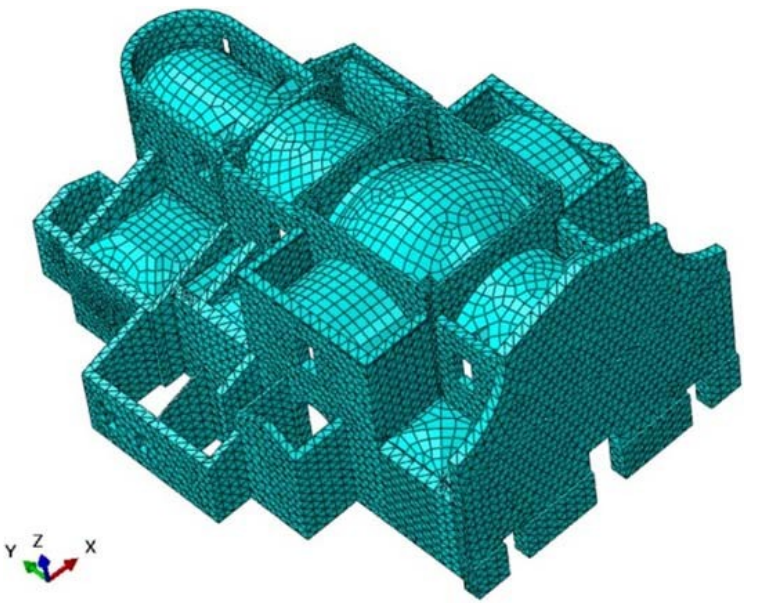

Figure 8: the finite element mesh 


\section{NUMERICAL ANALYSES}

Different types of analysis were carried out on the model for an in-depth view of the structural behaviour. In the elastic field, after a static analysis to assess the general stress levels and distribution in normal loading conditions, a modal analysis was performed to investigate the characteristics of the dynamic response. The first periods are around 0.3 seconds, a reasonable value for these structures. The first three modes are in fig. 9. While the second mode is transversal and involves the main body of the church including the vault system, the main mode and the third both concentrate mainly on the façade. Their modal shapes resemble the corresponding damage mechanisms. The modes indicate, thus, an enhanced out-of-plane deformability of the gable that could possibly evolve into the corresponding damage pattern, which is somewhat inconsistent with the actual outcome that saw little damage to this part. This question has been the particular focus of further analyses.
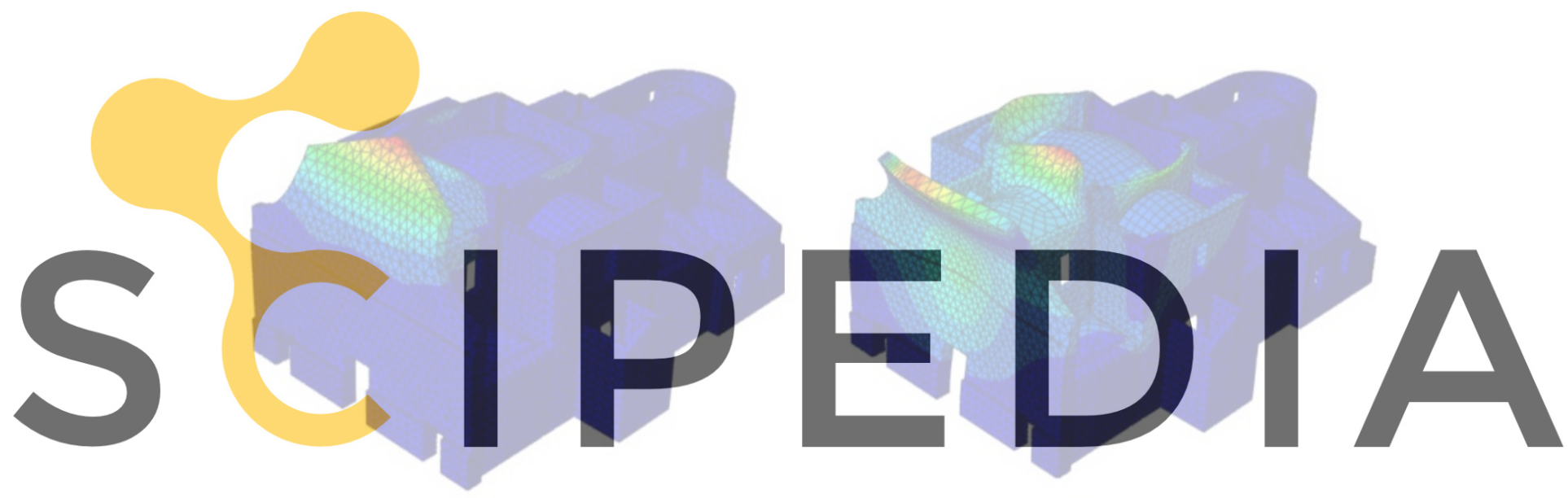

Register for free at https//www.scipedia.com to download the version without the watermark
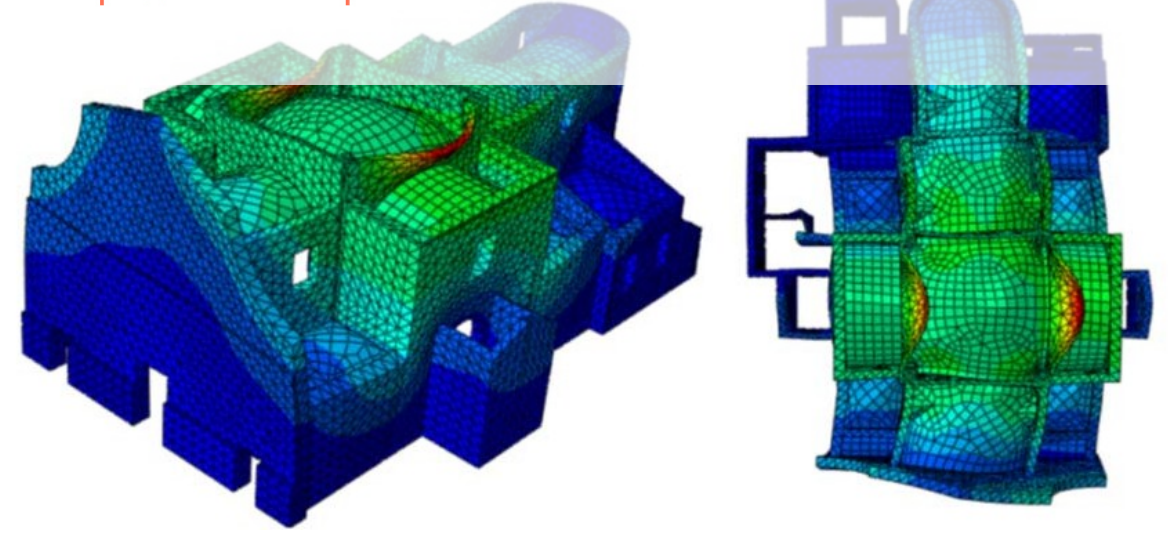

Figure 9: first and third modal shape (top) and second modal shape with two views (bottom)

In order to perform seismic analyses, reference has been made to recordings from the station of Poggio Rusco, the closest to the area, in the EW direction, making reference to the event of May 29 at 9: 0002 a.m., which had been the most damaging. The response spectrum 
derived from the recording is shown in fig. 10, together with the elastic design spectrum with return period of 475 years given by the Italian Design Code at the church coordinates.
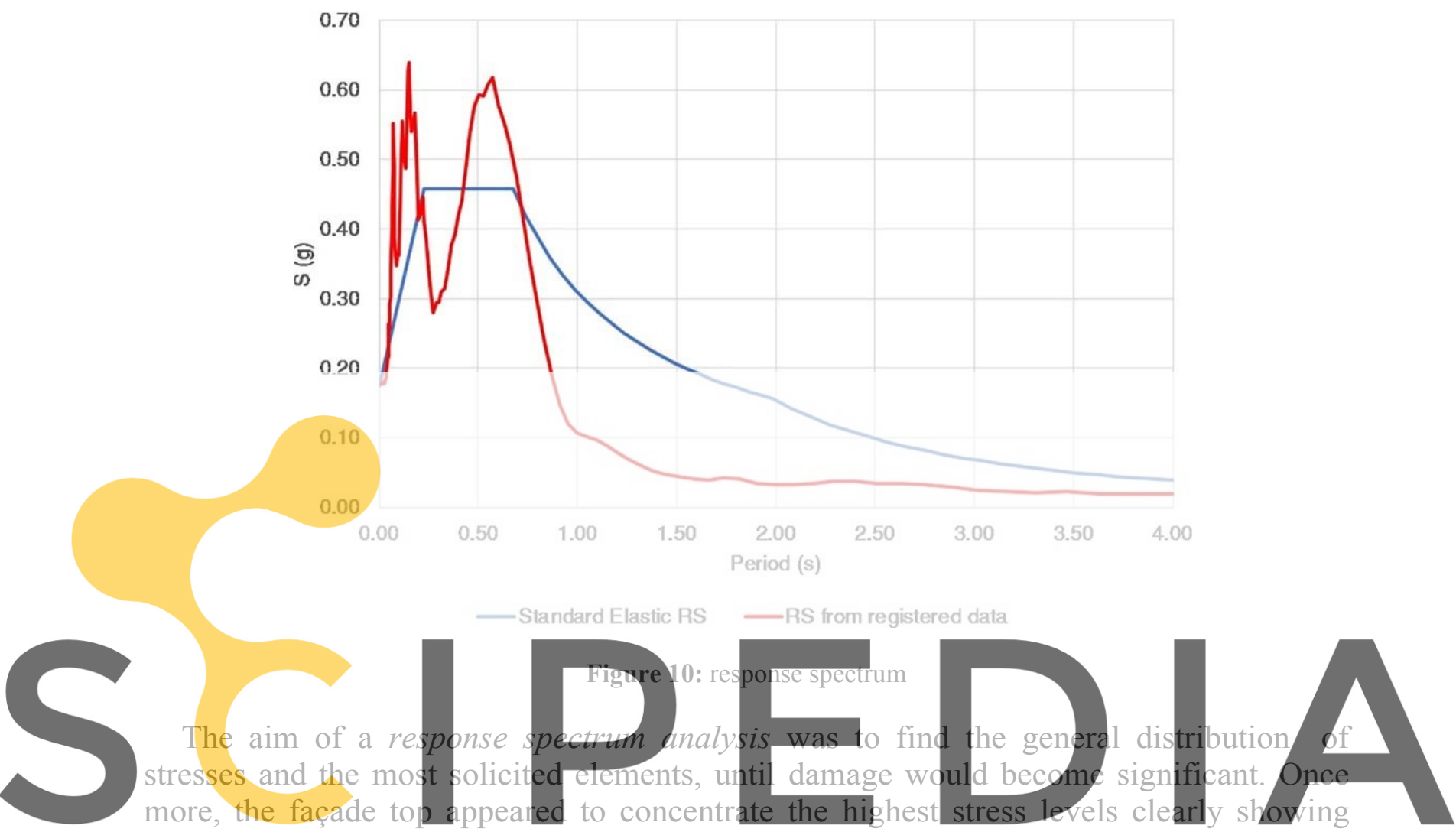

out-of-plane bending, as in fig. 11. Vaults and arches, especially those close to the

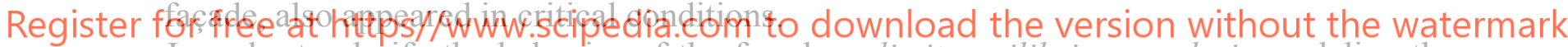
In order to clarify the behavior of the façade, a limit equilibrium analysis modeling the overturning of the gable was performed with non-linear kinematic approach. The acceleration activating the mechanism resulted lower than the peak ground acceleration and the spectral acceleration occurred during the earthquake, once more indicating failure of this element.

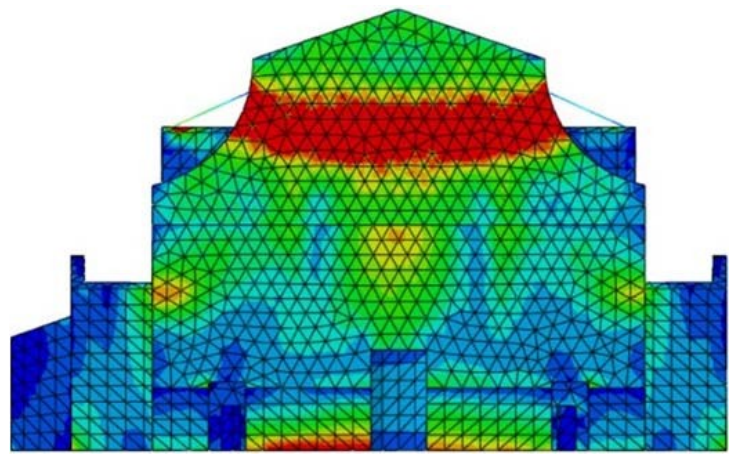

Figure 11: tensile stress distributions, where blue is null and red the maximum value 
The analyses discussed so far could not consider the effect of duration of the earthquake, and of possible variations in the structural behavior with time. In order to shed light on this point, a nonlinear time-history analysis was performed. The nonlinearity of the material was modeled through a concrete plasticity model available in Abaqus [9] and calibrated for masonry, as several cases found in the literature suggested. Nonlinearity and the size of the full model would require an unreachable computational effort. Since the focus of this analysis was the front area, only this part has been studied, with reference to the significant duration of motion [10].

In order to adopt a reduced but significant model, extension and boundary conditions of the reduced models have been based on a calibration comparing periods and modes of the reduced part with the full model. The final simplified model, shown in fig. 12, had 31336 finite elements, which made computations still demanding but feasible on a high capacity computer.

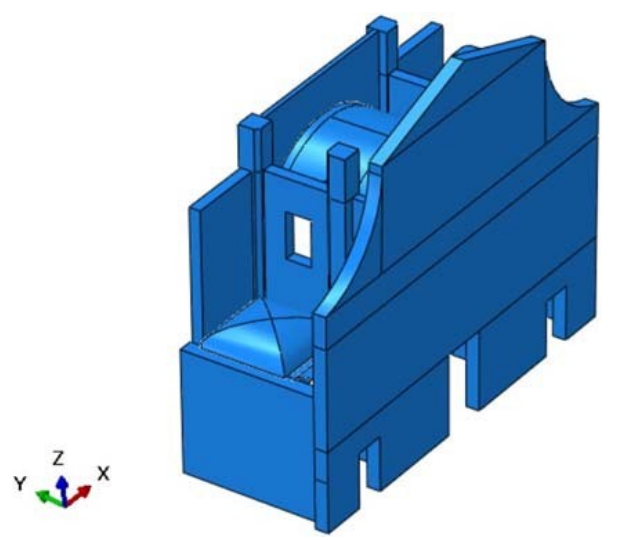

Figure 12: reduced model for nonlinear analysis
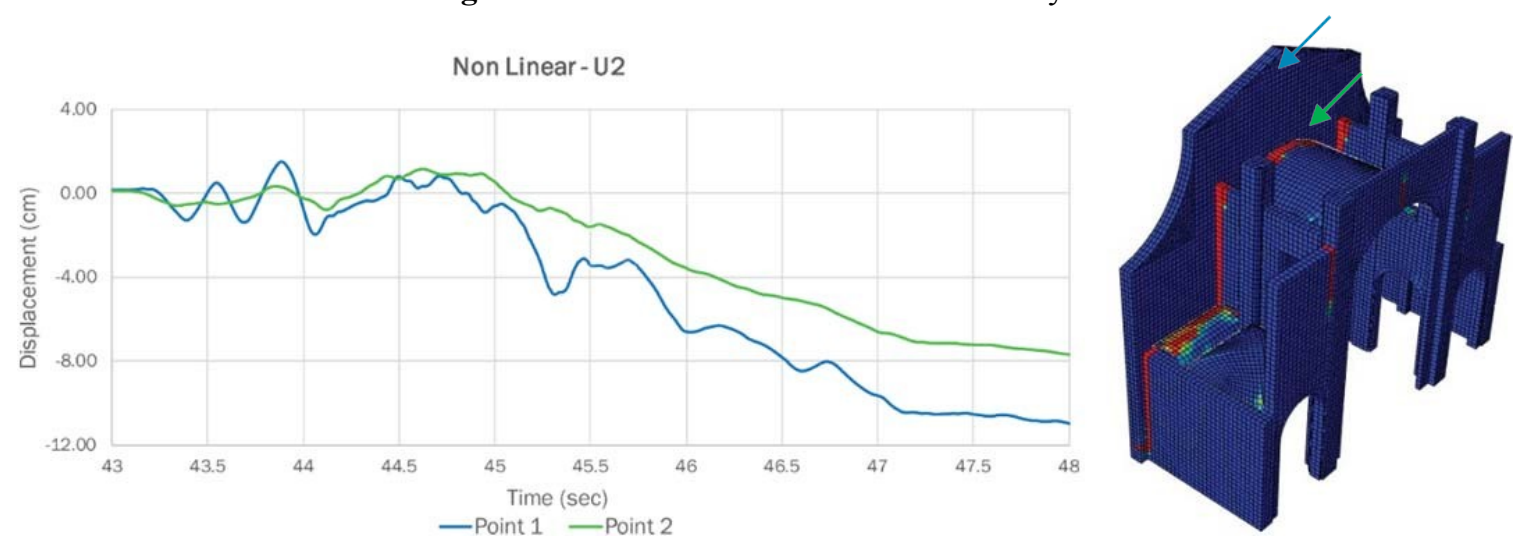

Figure 13: development of displacements at the vertex (blue, dark line) and at the connection of façade and vault (green, light line), see arrows, and model in damaged conditions along the red line

Results may be summarized making reference to fig. 13. An initial oscillation occurs at the top, until the connection of the façade with the back part deteriorates; at this time, the entire façade is weakly restrained and a trend toward a full façade rotation sets in. 
Meanwhile, larger displacements occur at the vault, now separated from the façade, bringing to its collapse. A switch from an initial gable mechanism to a façade overtopping one has avoided further development of the first; damage in the second has also developed partially. The situation could not be described without a time history analysis, but the reference to codified damage mechanisms has helped in pointing out this particular situation.

\section{CONCLUSIONS}

- The usefulness of making reference to a classification by mechanisms for damage description has once more been confirmed.

- For the façade, response spectrum and limit equilibrium analyses had indicated the out-of-plane failure of the tympanum as the first mechanism likely to develop. The real damage was better interpreted by a non-linear time-history analysis showing the initial involvement of the tympanum subsequently controlled by the establishing of a global façade mechanism.

- Recent possibilities of geometric representation of 3D models with vector graphics proved to be a step forward in the understanding of complex existing structures.

Acknowledgements. Research partially funded by Reluis-DPC Project 2019-21. The authors wish to thank Arch. Anna Maria Basso Bert, Soprintendenza Archeologia, Belle Arti e Paesaggio per le province di Bergamo e Brescia, for making this study possible, giving access to documental material and damage data.

\section{REFERENCES}

[1] Lagomarsino, S. and Podestà, S. Seismic vulnerability of ancient churches: part 1. Damage assessment and emergency planning, Earthq. Spectra (2004) 20(2): 377-394.

[2] MiBAC, (2006). Scheda per il rilievo del danno ai beni culturali - Chiese, modello A-DC.

[3] Sorrentino, L., Liberatore, L., Decanini, D. and Liberatore, D. The performance of churches in the 2012 Emilia earthquakes, Bull. of Earthq. Eng. (2014), 12: 2299-2331.

[4] Parisi, M.A. and Chesi, C. (2019) Structural characterization for the seismic protection of heritage churches, In: R. Aguilar et al. (Eds.): Structural Analysis of Historical Constructions, RILEM Bookseries 18: 1392-1400.

[5] Binda, L., Chesi, C. and Parisi, M.A. (2010) Seismic Damage to Churches: Observations from the L'Aquila, Italy, Earthquake and Considerations on a Case-study, Adv. Mat. Res., 133-134: 641-646.

[6] Sferrazza Papa G, Silva B (2018) Assessment of Post-Earthquake Damage: St. Salvatore Church in Acquapagana, Central Italy. Buildings 8: 45

[7] Rhinoceros (2019). User manual, version 6.0, Robert McNeel \& Associates.

[8] Parisi M.A. and Chesi C. (2014) Seismic vulnerability of traditional buildings: the effect of roof-masonry walls interaction. In: Proceedings 10th U.S. NCEE, Anchorage, Alaska.

[9] Abaqus. (2016). Theory manual, version 2016.

[10] Trifunac, M.D. and Brady, A.G. (1975). A study on the duration of strong earthquake ground motion. Bulletin of the Seismological Society of America, 65(3):581 